\title{
Reduction in the number of CGG repeats on the FMR1 gene in carriers of genetic disorders versus noncarriers
}

\author{
Alexandra Peyser ${ }^{1}$, Tomer Singer ${ }^{1}$, Christine Mullin $^{1}$, Avner Hershlag ${ }^{1}$ \\ ${ }^{1}$ Department of Obstetrics and Gynecology, Northwell Health, Division of Reproductive Endocrinology, \\ Hofstra-Northwell School of Medicine, New York, USA
}

\begin{abstract}
Objective: CGG repeat expansion on the fragile $X$ mental retardation 1 (FMR1) gene is used to diagnose fragile $X$ syndrome. Previous studies have discussed the correlation between the number of CGG repeats and its associated phenotypic components. The objective of this study is to determine whether the number of CGG repeats differ between carriers of genetic disorders versus noncarriers.

Methods: We performed a retrospective chart review of 2867 patients who received genetic screening at our fertility clinic between June 2013 and July 2015. The number of CGG repeats on allele 1 and allele 2 on the FMR1 gene was collected and it was specified whether the patient was a carrier or a noncarrier of a specific mutation. Patients with CGG repeats greater than or equal to 45 were excluded from the study.

Results: Carriers $(n=759)$ had a reduced number of repeats compared to noncarriers $(n=2024)$ on allele 1 $(p=.03)$, allele $2(p=.02)$ and the average of both alleles $(p=.01)$. Additionally, the number of CGG repeats from the ten most carried diseases from the cohort were used and tested individually for clinical significance against the number of repeats in the noncarriers. A reduction in repeats was shown in several mutations and a few were outliers.

Conclusion: Our results demonstrate that there is a significant reduction in the number of CGG repeats in carriers of genetic mutations. A larger scale study of disease carrying patients would be beneficial.
\end{abstract}

Keywords: FMR1, carrier screening, CGG repeats

\section{INTRODUCTION}

The fragile $X$ syndrome is one of the most common causes of inherited mental retardation. The disorder is a result of intergenerational instability of a trinucleotide CGG repeat expansion located on the $5^{\prime}$ translated region of the $\mathrm{X}$-linked fragile $\mathrm{X}$ mental retardation 1 (FMR1) gene (Brown, 2002). The full mutation occurs when there are greater than 200 CGG repeats on the FMR1 gene, which results in the gene becoming fully methylated and thus silenced. The numbers of CGG repeats fall into four categories based on their stability: normal (up to 44 CGG repeats); intermediate (45-54 repeats); premutation (55200 ); and full mutation (>200 repeats) (Maddalena et al., 2001). Some recent studies have used a lower boundary to define the beginning of the intermediate stage (e.g., 41 CGG repeats) (Hall et al., 2011).

Repeat expansion in the "premutation" range, between 55 and 200, can cause distinct clinical manifestations or neuropsychological changes. Disorders such as fragile $X$-associated tremor/ataxia syndrome (FXTAS) and fragile $X$-associated premature ovarian insufficiency have been associated with the premutation (Loesch \& Hagerman 2012).

Many studies have correlated the number of CGG repeats with a phenotypic presentation (Mailick et al., 2014). For example, studies have looked at whether the number of CGG repeats differs in patients with Parkinson's Disease, Essential Tremor, and Multiple Sclerosis (Cilia et al., 2009; Clark et al., 2015; Zhang et al., 2009). Patients with the premutation alleles have been described to have additional phenotypic components such as developmental problems, autism spectrum disorders, attention deficit hyperactivity disorders, shyness, anxiety and seizures. Fibromyalgia and hypothyroidism have also been found to be more common in carriers of the premutation compared to controls (Rodriguez-Revenga et al.,2009; Roberts et al., 2009; Hessl et al., 2005; Bourgeois et al., 2011; Coffeyet al., 2008).

A lower-than-normal range of CGG has been associated with a myriad of clinical presentations, ranging from increased thirst and memory loss to a higher incidence of breast and uterine cancer, as well as increased risk of having a child with developmental impairment or mental disability (Mailick et al., 2014).

Only a few studies have examined the relationship between CGG repeats and the genotypic makeup of patients. BRCA1/2 mutation carriers have been shown to have distinctly lower CGG repeats compared to the general population (Weghofer et al., 2012). It has been theorized that BRCA1/2 mutations may be embryo-lethal, unless rescued by low CGG repeats in the FMR1 genes. However, this assumption has been disputed by other studies (Dagan et al., 2014).

The objective of this study is to determine whether the number of CGG repeats differs between carriers of various genetic disorders compared to noncarriers.

\section{MATERIALS AND METHODS}

Genetic screening results were collected from women that came into our fertility clinic between June 2013 and July 2015. Genetic screening was done on a blood sample from the patient and it was tested for mutations in 102 clinically significant genes (Counsyl ${ }^{\circledR}$, San Francisco, CA., USA). The number of CGG repeats on allele 1 and allele 2 of the FMR1 gene was also obtained from the genetic results, as well as whether the patient was a carrier or a noncarrier of one or several gene mutations. Patients with CGG repeats greater or equal to 45 were excluded from the study due to the potential of those with the 'intermediate' number to have Fragile $X$. The averages of the CGG repeats on allele 1 and allele 2 were obtained for carriers and noncarriers.

Additionally, the ten most carried diseases within our center were obtained and the CGG distribution for each disease was collected. The ten most carried diseases were: Hb Beta Chain-Related Hemoglobinopathy, Cystic Fibrosis, Pseudocholinesterase Deficiency, Spinal Muscular 
Atrophy, Alpha-1 Antitrypsin Deficiency, GJB2-related DFNB1 nonsyndromic hearing loss and deafness, Gaucher Disease, Familial Mediterranean Fever, Smith-Lemli-Opitz Syndrome and Achromatopsia. The average of the CGG repeats for carriers of genetic diseases was tested for clinical significance and compared to the noncarriers. The CGG distribution for each disease was also individually tested for significance against noncarriers.

Triple repeat detection was done by PCR to size the CGG repeat in the 5' UTR region of the FMR1 (NM_002024.4: c.1131CGG[1_n]). PCR products generated from fluorescently labeled primers are detected by gel electrophoresis. Reported sizes are accurate to +/- 1 repeat for up to 200 repeats. All laboratory investigations were performed using commercial assays (Counsyl ${ }^{\circledR}$, San Francisco, Ca., USA).

The distribution of the CGG repeats in women with and without a carrier mutation was compared using the statistical t-test when appropriate, at 5\% significance level.

\section{RESULTS}

In total, the study included 2,867 women who received genetic screening. Of those, 843 (mean age $35.9 \pm 5.4 \mathrm{y}$ ) were carriers of one or more genetic diseases, and 2024 (mean age $35.7 \pm 5.0 y$ ) were noncarriers. 84 women were excluded from the carrier cohort because they had CGG repeats greater than or equal to 45 . Therefore, 759 carriers of a genetic mutation were included in the study.

Table 1 outlines the average number of CGG repeats for carriers, noncarriers and the top ten carrier mutations at our center. Carriers had lower CGG repeat values compared to noncarriers for allele $1(p=.03)$, allele $2(p=.02)$ and the average of both alleles $(p=.01)$. Allele 1 repeats in carriers of Alpha-1 Antitrypsin, Gaucher, Familial Mediterranean Fever and Smith-Lemli-Opitz Syndrome had significantly lower repeats than noncarriers. $(p=.01, p=.02, p=.02$, $p=.01$, respectively). Allele 2 repeats in carriers of Alpha- 1 Antitrypsin, Gaucher and Smith-Lemli-Opitz Syndrome had lower repeats than noncarriers $(p=.02, p=.01, p=.05$, respectively). The average of both allele 1 and allele 2 in Alpha-1 Antitrypsin, Gaucher and Smith-Lemli-Opitz Syndrome carriers demonstrated significantly reduced
CGG repeats than noncarriers. $(p=.003, p=.004, p=.009)$. No significant difference was noted in any of the other CGG distributions within the other diseases.

\section{DISCUSSION}

This study evaluated whether there is a correlation between the numbers of CGG repeats in carriers of genetic mutations versus noncarriers, to determine whether CGG repeats differ between the two groups. We evaluated 2867 women who were screened for genetic mutations. Overall, carriers had a lower number of CGG repeats than noncarriers. However, several mutations were outliers. Weghofer et al. (2012) described an association between low CGG repeats and BRCA1/2 positive women. They suggested that low numbers of CGG's rescued embryos carrying the BRCA $1 / 2$ mutation. If a human embryo carries a low allele $(<26)$, then the embryo is able to overcome the BRCA1/2- associated embryo lethality. Additionally, they hypothesized that BRCA1/2 mutations may somehow be able to influence CGG repeat expansion.

Another trinucleotide pattern, the CAG repeat, has been found to be associated with a higher risk of cryptorchidism in patients with shorter repeats. It has been hypothesized that there is an indirect influence whereby the shorter CAG repeats create lower testosterone levels and, therefore, influence the androgen receptor mediated genomic pathway associated with cryptorchidism (Davis-Dao et al., 2012).

The mechanism by which the carrier status can cause a reduction in the number of CGG repeats or vice-versa could be a result of an indirect relationship between the transcription of the FMR1 gene and the genes responsible for the carrier mutation. Mechanistic investigations are needed to identify these indirect or direct effects.

A limitation to our study is the small sample size. Indeed, a larger cohort with more carriers would be beneficial.

In conclusion, this preliminary investigation suggests that carriers of genetic mutations have less CGG repeats on the FMR1 gene when compared to noncarriers. Larger epidemiological studies of disease carrying patients as well as analysis of genomic pathway mechanisms may be beneficial.

Table 1. Average number of CGG repeats for carriers and noncarriers on allele 1 , allele 2 and the average of alleles 1 and 2

\begin{tabular}{|l|c|c|c|}
\hline Disease & CGG Allele 1 (Mean) & CGG Allele 2 (Mean) & Avg. of Both Alleles \\
\hline Hb Beta $(n=93)$ & $28.20 \pm 3.7$ & $31.58 \pm 4.0$ & $29.90 \pm 3.3$ \\
\hline Cystic Fibrosis $(n=90)$ & $27.92 \pm 3.6$ & $31.39 \pm 3.6$ & $29.66 \pm 3.0$ \\
\hline Pseudocholinesterase $(n=65)$ & $27.62 \pm 4.2$ & $31.97 \pm 4.2$ & $29.79 \pm 3.3$ \\
\hline SMA $(n=48)$ & $28.23 \pm 3.7$ & $31.06 \pm 2.9$ & $29.65 \pm 2.4$ \\
\hline GJB2 $(n=47)$ & $27.60 \pm 4.2$ & $31.21 \pm 4.7$ & $29.40 \pm 3.7$ \\
\hline Gaucher $(n=43)$ & $26.51+4.7$ & $30.33 \pm 3.3$ & $28.42 \pm 3.4$ \\
\hline Alpha-1 Antitrypsin $(n=39)$ & $26.41 \pm 4.9$ & $30.41 \pm 3.3$ & $28.41 \pm 3.5$ \\
\hline Smith-Lemli-Opitz & $26.43 \pm 4.3$ & $30.60 \pm 2.3$ & $28.51 \pm 2.7$ \\
\hline Syndrome $(n=35)$ & $26.41 \pm 4.8$ & $31.74 \pm 4.1$ & $29.10 \pm 3.6$ \\
\hline FMF $(n=34)$ & $28.87 \pm 3.4$ & $31.00 \pm 2.9$ & $29.93 \pm 2.3$ \\
\hline Noncarriers $(n=2024)$ & $27.82 \pm 3.9$ & $31.55 \pm 3.5$ & $29.69 \pm 3.3$ \\
\hline Carriers $(n=759)$ & $27.50 \pm 4.3$ & $31.25 \pm 3.6$ & $29.37 \pm 3.2$ \\
\hline Abreviations: & . & & \\
\hline
\end{tabular}

Abbreviations: Hb-Beta, Hb Beta Chain-Related Hemoglobinopathy; SMA, Spinal Muscular Atrophy; GJB2, GJB2-related DFNB1 nonsyndromic hearing loss and deafness; FMF - Familial Mediterranean Fever. 


\section{HUMAN STUDIES AND INFORMED CONSENT STATEMENT}

All procedures followed were in accordance with the ethical standards of the responsible committee on human experimentation (institutional and national) and with the Helsinki Declaration of 1975, as revised in 2000. Informed consent was obtained from all patients for being included in the study. The Northwell Health Institutional Review Board reviewed and approved this study.

\section{CONFLICT OF INTEREST}

The authors declare no conflict of interest.

\section{Corresponding Author:}

Alexandra Peyser

Department of Obstetrics and Gynecology

Northwell Health

Division of Reproductive Endocrinology

Hofstra-Northwell School of Medicine

Manhasset, New York, USA

E-mail: peysera@gmail.com

\section{REFERENCES}

Bourgeois JA, Seritan AL, Casillas EM, Hessl D, Schneider A, Yang Y, Kaur I, Cogswell JB, Nguyen DV, Hagerman RJ. Lifetime prevalence of mood and anxiety disorders in fragile X premutation carriers. J Clin Psychiatry. 2011;72:175-82. PMID: 20816038 DOI: 10.4088/JCP.09m05407blu

Brown WT. The Molecular Biology of the Fragile X Mutation. In: Hagerman R, Hagerman PJ, eds. Fragile X Syndrome: Diagnosis, Treatment, and Research. 3rd ed. Baltimore: Johns Hopkins University Press; 2002. p. 110-35.

Cilia R, Kraff J, Canesi M, Pezzoli G, Goldwurm S, Amiri K, Tang HT, Pan R, Hagerman PJ, Tassone F. Screening for the presence of FMR1 premutation alleles in women with parkinsonism. Arch Neurol. 2009;66:244-9. PMID: 19204162 DOI: 10.1001/archneurol.2008.548

Clark LN, Ye X, Liu X, Louis ED. Genetic analysis of FMR1 repeat expansion in essential tremor. Neurosci Lett. 2015;593:114-7. PMID: 25796179 DOI: 10.1016/j.neulet.2015.03.027

Coffey SM, Cook K, Tartaglia N, Tassone F, Nguyen DV, Pan R, Bronsky HE, Yuhas J, Borodyanskaya M, Grigsby J, Doerflinger M, Hagerman PJ, Hagerman RJ. Expanded clinical phenotype of women with the FMR1 premutation. Am J Med Genet A. 2008;146A:1009-16. PMID: 18348275 DOI: 10.1002/ajmg.a.32060

Dagan E, Cohen Y, Mory A, Adir V, Borochowitz Z, Raanani H, Kurolap A, Melikhan-Revzin S, Meirow D, Gershoni-Baruch R. BRCA1/2 mutations and FMR1 alleles are randomly distributed: a case control study. Eur J Hum Genet. 2014;22:277-9. PMID: 24281364 DOI: 10.1038/ejhg.2013.281

Davis-Dao C, Koh CJ, Hardy BE, Chang A, Kim SS, De Filippo R, Hwang A, Pike MC, Carroll JD, Coetzee GA, Vandenberg D, Siegmund K, Cortessis VK. Shorter androgen receptor CAG repeat lengths associated with cryptorchidism risk among Hispanic white boys. J Clin Endocrinol Metab. 2012;97:E393-9. PMID: 22188741 DOI:

\subsection{0/jc.2011-2439}

Hall DA, Berry-Kravis E, Zhang W, Tassone F, Spector E, Zerbe G, Hagerman PJ, Ouyang B, Leehey MA. FMR1 gray-zone alleles: association with Parkinson's disease in women? Mov Disord. 2011;26:1900-6. PMID: 21567456 DOI: $10.1002 /$ mds. 23755

Hessl D, Tassone F, Loesch DZ, Berry-Kravis E, Leehey MA, Gane LW, Barbato I, Rice C, Gould E, Hall DA, Grigsby J, Wegelin JA, Harris S, Lewin F, Weinberg D, Hagerman PJ, Hagerman RJ. Abnormal elevation of FMR1 mRNA is associated with psychological symptoms in individuals with the fragile X premutation. Am J Med Genet B Neuropsychiatr Genet. 2005;139B:115-21. PMID: 16184602 DOI: 10.1002/ajmg.b.30241

Loesch D, Hagerman R. Unstable mutations in the FMR1 gene and the phenotypes. Adv Exp Med Biol. 2012;769:78114. PMID: 23560306

Maddalena A, Richards CS, Mcginniss MJ, Brothman A, Desnick RJ, Grier RE, Hirsch B, Jacky P, McDowell GA Popovich B, Watson M, Wolff DJ. Technical standards and guidelines for fragile $X$ : the first of a series of disease-specific supplements to the Standards and Guidelines for Clinical Genetics Laboratories of the American College of Medical Genetics. Quality Assurance Subcommittee of the Laboratory Practice Committee. Genet Med. 2001;3:200-5. PMID: 11388762 DOI: 10.109700125817-200105000-00010

Mailick MR, Hong J, Rathouz P, Baker MW, Greenberg JS, Smith L, Maenner M. Low-normal FMR1 CGG repeat length: phenotypic associations. Front Genet. 2014;5:309. PMID: 25250047 DOI: $10.3389 /$ fgene.2014.00309

Roberts JE, Bailey DB Jr, Mankowski J, Ford A, Sideris J, Weisenfeld LA, Heath TM, Golden RN. Mood and anxiety disorders in females with the FMR1 premutation. Am J Med Genet B Neuropsychiatr Gene. 2009;150B:130-9. PMID: 18553360 DOI: $10.1002 / a j m g . b .30786$

Rodriguez-Revenga L, Madrigal I, Pagonabarraga J, Xunclà M, Badenas C, Kulisevsky J, Gomez B, Milà M. Penetrance of FMR1 premutation associated pathologies in fragile $X$ syndrome families. Eur J Hum Genet. 2009;17:1359-62. PMID: 19367323 DOI: 10.1038/ejhg.2009.51

Weghofer A, Tea MK, Barad DH, Kim A, Singer CF, Wagner $\mathrm{K}$, Gleicher N. BRCA1/2 mutations appear embryo-lethal unless rescued by low (CGG $n<26)$ FMR1 sub-genotypes: explanation for the 'BRCA paradox'? PLoS One. 2012;7:e44753. PMID: 22984553 DOI: 10.1371/journal.pone.0044753

Zhang L, Coffey S, Lua LL, Greco CM, Schafer JA, Brunberg J, Borodyanskaya M, Agius MA, Apperson M, Leehey M, Tartaglia N, Tassone F, Hagerman PJ, Hagerman RJ. FMR1 premutation in females diagnosed with multiple sclerosis. J Neurol Neurosurg Psychiatr. 2009;80:812-4. PMID: 19531693 DOI: $10.1136 /$ jnnp.2008.160960 